\title{
Persistence and remission of depressive symptoms and psycho-social correlates in Chinese early adolescents
}

\author{
Xinli Chi', Benjamin Becker ${ }^{2}$, Qian Yư ${ }^{1,3}$, Md Mahhub Hossain ${ }^{4}$, Jingyaun Lin ${ }^{3}$, Albert Yeung ${ }^{5}$, \\ Radhika Seiler-Ramadas ${ }^{6}$, Igor Grabovac ${ }^{6}, \mathrm{He} \mathrm{Bu}^{7}, \mathrm{Fei} \mathrm{Xie}^{8}$ and Liye Zou ${ }^{1,3^{*}}$
}

\begin{abstract}
Background: This study aimed to investigate a one-year course of persistent/remitted depressive symptoms and associated demographic and psychosocial factors that predict persistent/remitted depressive symptoms in Chinese high school students.

Methods: One thousand five hundred forty-four Grade 7 students provided data for the first wave. Of the initially recruited students, 483 who were classified as depressed (CESD score $\geq 16)$ at baseline were then tracked and invited to fill in the questionnaire for a second time (Grade 8) after 1 year. Finally, 435 of them were successfully matched.

Results: Two hundred two (46.4\%) of the subset categorized as depressed in the first survey $(N=435)$ remained with depressive symptoms, while 233 (53.6\%) recovered from depression 1 year later. Having siblings, a lower level of positive youth development, non-intact family status, and poor family functioning at baseline significantly predicted a higher likelihood of persistent depression, while those with fathers having higher educational qualifications (bachelor's degree or higher) at baseline showed a significantly higher probability of remitting from depression.

Conclusions: The findings indicated that the prevalence of persistent depressive symptoms was generally high, and promoting aspects of positive youth development and family functioning for adolescents could be promising in preventing or reducing these symptoms.
\end{abstract}

Keywords: Persistent depressive symptoms, Positive youth development, Family functioning, Chinese adolescents

\section{Background}

Depression is one of the leading causes of adolescent illness and disability, which is associated with serious detrimental consequences such as social and educational dysfunction, substance abuse, aggression, bingeing, and high risks of suicide [1]. As a result, depression not only

\footnotetext{
* Correspondence: liyezou123@gmail.com

'Center for Lifestyle and Mental Health, School of Psychology, Shenzhen University, Shenzhen 518060, China

${ }^{3}$ Exercise \& Mental Health Laboratory, School of Psychology, Shenzhen University, Shenzhen 518060, China

Full list of author information is available at the end of the article
}

impairs the normal psychosocial development of the adolescents, but also places a substantial financial burden (juvenile justice and education programs, for example) on the family of depressed adolescents and the society [2]. Earlier observational studies found high prevalence rates of depression among adolescents alongside several potential risks and/or protective factors [3-5]. However, due to the cross-sectional design of previous studies, in which data are gathered only at single time points, the persistence of depressive symptoms and the effects of risk and/or protective factors on the course of depressive

(c) The Author(s). 2020 Open Access This article is licensed under a Creative Commons Attribution 4.0 International License, which permits use, sharing, adaptation, distribution and reproduction in any medium or format, as long as you give appropriate credit to the original author(s) and the source, provide a link to the Creative Commons licence, and indicate if changes were made. The images or other third party material in this article are included in the article's Creative Commons licence, unless indicated otherwise in a credit line to the material. If material is not included in the article's Creative Commons licence and your intended use is not permitted by statutory regulation or exceeds the permitted use, you will need to obtain permission directly from the copyright holder. To view a copy of this licence, visit http://creativecommons.org/licenses/by/4.0/ The Creative Commons Public Domain Dedication waiver (http://creativecommons.org/publicdomain/zero/1.0/) applies to the data made available in this article, unless otherwise stated in a credit line to the data. 
symptomatology in adolescence remain largely unknown. Notably, factors that contribute to the onset of depressive symptomatology in adolescence may differ from those that lead to the persistence of depression. Therefore, exploring the temporal trajectory of adolescent depression may lead to a more robust and accurate determination of risk factors than a single-time assessment of depressive symptoms [6, 7]. Given the high prevalence rates and detrimental impacts of adolescent depression, a better understanding of persistent depressive symptoms during adolescence and associated risks and/ or protective factors is urgently needed. Moreover, the results can be used by key stakeholders including the policy-makers, health professionals, and parents, to identify subjects vulnerable to persistent depression and to develop more effective early interventional approaches to prevent the same.

The prevalence rates of persistent depressive symptoms in adolescents are found to vary greatly across countries, regions, and populations. For example, one study conducted in the USA included 1176 adolescents who reported depressive symptoms at baseline and indicated that $38.5 \%$ of them exhibited persistent depressive symptoms within a 12-month follow-up period [8]. In addition, many longitudinal studies with different follow-up periods (6-months, three-years, and 10-years) conducted in Switzerland, the UK, and Germany reported early and late adolescents with either depression alone $[9,10]$ or depression with coronary heart disease [11]. In these studies, the baseline and post-assessment of persistent depressive symptoms were reported with prevalence rates ranging from 5 to $12.2 \%$. Likewise, Chinese scholars recently conducted one longitudinal study where they focused on middle school adolescents. The study conducted in Guangzhou included 5365 students, with 735 that were reported with depression at baseline and $57.14 \%$ of initially self-reported depressed participants having remained with symptoms after 9 months [12]. Admittedly, the results of the aforementioned studies provide valuable information as the majority of studies that have investigated the prevalence of persistent depression in adolescents were conducted in Western countries (e.g., USA and Europe). However, depression among Chinese adolescents from metropolitan areas like Shenzhen, and those who study in highly competitive academic environments remains poorly investigated. As such, we conducted a two-wave longitudinal study with data collected at baseline and an interval of 1 year to investigate the prevalence of persistence/remission of depressive symptoms in Chinese adolescents.

Moreover, to prevent adolescent depression at an early stage, it is essential to identify potential factors that may have contributed to depression in this age group. Based on developmental psychopathology perspective [13, 14], the development of depression in youth was jointly influenced by genetic, biological, psychological, and social factors. Of them, demographic, psychological, and familial factors were very likely to have influences on the onset and persistence of adolescent depression [15, 16]. Using developmental psychopathology framework, we focused on whether personal factors including demographics (i.e. age, gender, sibling [presence or absence], migrant status), psychological factor (i.e., positive youth development), and familial factors (i.e., parents' education level, family structure, and family function) are related to the persistence of depression among Chinese adolescents.

Empirically, it was reported that adolescents were more susceptible to depression with increasing age [17], if they were biologically female, migrant students [18], had sibling(s), and/or a non-intact family (e.g., divorced families and single-parent families) $[19,20]$. On the other hand, higher positive youth development (PYD) (e.g., selfefficacy, resilience, and positive identity) and greater parental educational attainment $[21,22]$ have been welldocumented to serve as a protective factor against negative developmental outcomes like depression [23]. Furthermore, there has been accumulating evidence supporting the idea that family functioning plays a major role in the development of depression [24]. Family functioning generally refers to the global family environment in terms of socialization and structure, including levels of harmony, relationship and interactions within the family, levels of conflict and cohesion, organization, and the quality of communication. Lower levels of family functioning were found to associate with a greater likelihood of developing adolescent depression [25-27]. Based on this earlier evidence, we hypothesized that older adolescent age, females, having sibling(s), migrant background, non-intact family, lower positive youth development, poor family functioning, as well as lower parental educational attainment, are factors that render adolescents more susceptible to persistent depressive symptoms.

Against this background, the present study had two aims. The first aim of the study was to examine the prevalence of persistent depressive symptoms over 1 year among Chinese adolescents. The second aim was to explore personal predictive factors (i.e., gender, age, sibling (presence or absence), migrant status, and positive youth development) and family predictive factors (i.e., parents' education level, family structure, and family function) of persistent depressive symptoms among Chinese adolescents.

\section{Method}

\section{Participants}

This study was conducted in Shenzhen city, which is a major metropolitan area in South China. Chinese 
students were recruited from junior secondary schools, and two surveys were completed within 1 year. During the study period in 2018 , there were $1,476,000$ students within more than 150 public junior high schools located in Shenzhen (Shenzhen Education Bureau, 2019). Of these public schools, six were randomly selected between October and November 2016, with 1544 Grade 7 students providing data for the first wave. Of the initially recruited students, 483 were classified as depressed (CESD score $>=16)$ at baseline and were then tracked and invited to fill in the questionnaire for a second time (Grade 8) between October and November 2017. Students who missed the school day in which the second survey was conducted or failed to put their identification numbers on the questionnaires were excluded. Finally, only 435 initially self-reported depressed participants were matched successfully with each participant's school number, implying an acceptable attrition rate of $9.9 \%$. The mean age of the participants in this study at baseline was $12.46(\mathrm{SD}=.65)$.

\section{Procedure}

Participants were invited to complete multiple questionnaires on PYD, family functioning, depression, and socialdemographic characteristics. Data collection was administered by two trained graduate students who gave standardized instructions within the classroom settings. One graduate student introduced the purpose of this study, while the other helped maintain classroom order. Students were required to sit separately, to not speak, and to not engage in discussion. The duration of the survey was approximately $20 \mathrm{~min}$. There was the consideration of the high levels of stigma against having a psychiatric disorder among Chinese and high degree of privacy [28]. All students and parents were informed at the time of consent. Procedures are detailed as follows. Firstly, the informed consent form was sent to principals of all surveyed schools for their approval and then forwarded to teachers who were in charge of their respective classes. All responsible teachers had distributed the important document to students and asked for voluntary signature(s) of their parents or legal guardian(s). The purpose of this study was clearly explained in the consent form. We only handed out questionnaires those children of parents(s) or legal guardian(s) who signed the consent form. The data collected would not be looked at individually and would be analyzed in an aggregated manner at the start of each session. Subsequently the data was published in a research paper with personal information being kept strictly confidential. The two trained graduate students were present throughout the administration process to answer participants' questions. This study was approved by the Human Research Ethics Committee of Shenzhen University and all principals of the surveyed schools.

\section{Measurements}

\section{Sociodemographic correlates}

Participants were invited to report on their age, gender ( $1=$ male and $2=$ female), and whether they were from a one-child family $(1=$ one child, $2=$ non-one child $)$. They also reported their parental education levels $(1=$ less than or middle school, $2=$ high school and college, $3=$ university, and $4=$ more than university) and whether they grew up in an intact family (coded as 1 ) or a nonintact family (coded as 2). The demographic data of the study participants are presented in Table 1.

Table 1 Characteristics of depressed participants at baseline $(N=435)$

\begin{tabular}{lll}
\hline Predictors & $\mathrm{n} / \mathrm{M}$ & $\% / \mathrm{SD}$ \\
\hline Individual factors & 12.46 & .65 \\
Age & & \\
Gender & 210 & 48.3 \\
$\quad$ Male & 220 & 50.6 \\
$\quad$ Female & 5 & 1.1 \\
$\quad$ Missing & & \\
Siblings & 152 & 34.9 \\
One Child & 283 & 65.1 \\
$\quad$ Non-one child & 0 & 0 \\
$\quad$ Missing & & \\
Migrant status & 100 & 23.0 \\
Migrant students & 332 & 76.3 \\
Local students & 3 & .7 \\
Missing & 4.36 & .70
\end{tabular}

\section{Familial factors}

Family intactness

Intactness 399

91.7

Non-intactness

Missing

.9

Father's Education Level

Less than or middle school $\quad 156 \quad 35.9$

High school or college $\quad 142 \quad 32.6$

University

More than university

Missing data

16.1

70

8.5

Mother's Education Level

Less than or middle school

High school or college

44.1

University

More than university

14.5

Missing data

6.7

amily Function 


\section{Dependent variable}

Depression The 20-item Center for Epidemiologic Studies Depression Scale (CES-D) was utilized to assess levels of depression, which is validated for Chinese population $[29,30]$. Participants were asked to rate how often they experienced symptoms related to depression in the past 7 days using a four-point Likert scale $(0=$ rarely or none of the time, $3=$ most or all of the time). The scores for each item were added up, which resulted in the 20-item sum score of a maximum of 60 (greater scores indicated a higher level of depressive symptoms). Notably, participants who scored less than 16 were healthy, whereas those who scored 16 or higher $(C E S-D \geq 16)$ were considered as depressed [31,32]. Prior studies have shown that the CES-D has good psychometric properties [33, 34]. The Cronbach's alphas for the present study were > .85 at each of the two assessments.

\section{Independent variables}

PYD The Chinese Positive Youth Development Scale (CPYDS) was used to measure 15 positive youth development constructs such as resilience, self-efficacy, and emotional competence [35, 36]. Example items on this scale include, "I am a filial person" and "I know my strengths and weaknesses". Participants were asked to select one of four options which best fit their own circumstance based on a four-point Likert scale $(0=$ strongly disagree, $3=$ strongly agree). In the present study, the average of the total score for CPYDS was adopted as an indicator of personal positive youth development, with higher scores representing higher psychological competencies. The CPYDS has demonstrated reliability and validity in the sample of Chinese adolescents in previous studies [35, 36]. The Cronbach's alphas were $>.95$ at each of the two assessments.

Family functioning The Chinese Family Assessment Instrument (CFAI) that consists of 9 items was adapted to assess the general family function [37]. Example items on this scale include, "We don't get along well together" and "We confide in each other". Participants were asked to select one of five options, which best fit their own condition on a 5-point Likert scale $(1=$ very similar, $5=$ very dissimilar $)$. The mean score was used to reflect family function, with higher mean scores representing better family functioning. The shortened 9-item CFAI has shown acceptable internal consistency in previous studies [38, 39]. The Cronbach's alphas were $>.85$ at each of the waves of assessment in the present study.

\section{Statistical analyses}

Firstly, frequencies and percentages were computed to examine the one-year prevalence of persistent and remitted depressive symptoms among Chinese adolescents. The percentages of adolescents whose CES-D scores indicated depression ( $\geq 16$ points) and those who recovered from depressive symptoms ( $<16$ points) were computed. Secondly, Chi-square tests and independent sample ttests were conducted to compare whether there were differences in the characteristics of participants between persistence of depression and remission of depression within 12 months. Thirdly, two multilevel logistic regression analyses (level 1: individual; level 2: familial) were conducted to examine the over-time predictive effects of independent variables on persistence/remission of depression across 12 months (Table 2). Depressive symptoms (persistent depressive symptoms were coded as 1 ; remitted depressive symptoms were coded as 0 ) at wave 2 were considered as the dependent variable. Independent variables at baseline, including age, gender, sibling presence, migrant status, level of positive youth development, were put in the first block (level 1), while parental educational level, family structure (family intactness), and family functioning were put in the second block (level 2). Poisson distributions were normally approximated to calculate the $95 \%$ confidence intervals (CI). Two-tailed test with a $p$ value of less than .05 was used to determine the level of significance, using SPSS Version 23.0.

\section{Results}

\section{Characteristics of participants at baseline}

As seen in Table 1, 50.6\% were female, $65.1 \%$ had sibling(s), and $76.3 \%$ were local children. Around one-third of the participants reported that parents' educational levels were high school or college education (father: 32.6\%; mother: 28.5\%). The majority of students (91.7\%) were from intact families. Participants generally reported a high level of positive youth development $(4.36 \pm .70)$ and good family functioning (3.72 \pm .80$)$.

\section{Prevalence of persistent depression among the participants over one year}

As shown in Table 3, 435 successfully matched adolescents at baseline reported depression with the CESD sum score of $\geq 16)$. After 12 months, $202(46.4 \%)$ of the initially self-reported depressed participants remained with depressive symptoms, while 233 (53.6\%) of them recovered from depression. Regarding continuous scores on CES-D over two wave of data, the mean score of CES-D at persistent depression group was 24.56 ( $\mathrm{SD}=7.40$, range from 16 to 50 points) at baseline and 25.28 ( $\mathrm{SD}=7.43$, ranging from 16 to 55 points) (Fig. 1). The mean score of CES-D 
Table 2 Multilevel logistic regression modelling results for persistence of depression across one year

\begin{tabular}{|c|c|c|c|c|}
\hline \multirow[t]{2}{*}{ Predictors } & \multicolumn{2}{|c|}{ Model 1} & \multicolumn{2}{|c|}{ Model 2} \\
\hline & $B$ & $\begin{array}{l}\text { OR and 95\% } \\
\text { C.I.for OR }\end{array}$ & B & $\begin{array}{l}\text { OR and 95\% } \\
\text { C.I.for OR }\end{array}$ \\
\hline \multicolumn{5}{|l|}{ Individual factors } \\
\hline Age & -.09 & $\begin{array}{l}.91 \\
(.66,1.26)\end{array}$ & -.14 & $.87(.62,1.22)$ \\
\hline Gender & & 1 & & \\
\hline Male & & $\begin{array}{l}1.01 \\
(.66,1.53)\end{array}$ & & 1 \\
\hline Female & .10 & & .07 & $\begin{array}{l}1.08 \\
(.70,1.67)\end{array}$ \\
\hline \multicolumn{5}{|l|}{ Siblings } \\
\hline One Child & & 1 & & 1 \\
\hline Non-one child & .79 & $\begin{array}{l}2.19 \\
(1.40,3.44) * *\end{array}$ & .74 & $\begin{array}{l}2.10 \\
(1.27,3.48) *\end{array}$ \\
\hline \multicolumn{5}{|l|}{ Migrant status } \\
\hline Migrant students & & 1 & & 1 \\
\hline Local students & -.13 & $.88(.53,1.44)$ & .03 & $\begin{array}{l}1.03 \\
(.61,1.73)\end{array}$ \\
\hline $\begin{array}{l}\text { Positive Youth } \\
\text { Development }\end{array}$ & -.39 & $.67(.50, .92)$ & -.29 & $.74(.53,1.05)$ \\
\hline \multicolumn{5}{|l|}{ Familial factors } \\
\hline \multicolumn{5}{|l|}{ Family intactness } \\
\hline Intactness & & & & 1 \\
\hline Non-intactness & & & 1.05 & $\begin{array}{l}2.87 \\
(1.16,7.12) *\end{array}$ \\
\hline \multicolumn{5}{|l|}{ Father's Education Level } \\
\hline $\begin{array}{l}\text { Less than or middle } \\
\text { school }\end{array}$ & & & & 1 \\
\hline High school or college & & & -.26 & $.77(.45,1.32)$ \\
\hline University & & & -.35 & $.71(.31,1.61)$ \\
\hline More than university & & & -1.46 & $\begin{array}{l}.23(.07, .76) \\
*\end{array}$ \\
\hline \multicolumn{5}{|l|}{ Mother's Education Level } \\
\hline $\begin{array}{l}\text { Less than or middle } \\
\text { school }\end{array}$ & & & & 1 \\
\hline High school or college & & & .08 & $\begin{array}{l}1.08 \\
(.63,1.86)\end{array}$ \\
\hline University & & & .31 & $\begin{array}{l}1.36 \\
(.56,3.27)\end{array}$ \\
\hline More than university & & & .86 & $\begin{array}{l}2.37 \\
(.68,8.25)\end{array}$ \\
\hline Family Function & & & -.30 & $\begin{array}{l}.74 \\
(.54,1.01) *\end{array}$ \\
\hline$-2 \times \log$ likelihood & 513.33 & & 494.88 & \\
\hline Cox \& Snell $R^{2}$ & .04 & & .09 & \\
\hline Nagelkerke $R^{2}$ & .06 & & .12 & \\
\hline
\end{tabular}

${ }^{*} p<.05,{ }^{* *} p<.01,{ }^{* * *} p<.001$

at remitted depression group was 23.57 ( $\mathrm{SD}=7.21$, ranging from 16 to 51 points) at baseline and 9.09 ( $\mathrm{SD}=4.06$, ranging from 0 to 15 points) (Fig. 1).

\section{Predictors of persistent depression among the} participants over one year

In the univariate analysis, five variables (sibling presence, positive youth development, family structure/intactness, educational attainment, and family functioning) were observed to significantly correlate with persistent depression (all $p$ values < .05). However, age, gender, and migrant status of the participants were not significantly related to their persistent/remitted depressive symptoms (all $p$ values $>.05$ ). Furthermore, Multilevel logistic regression showed that on the individual level, presence of siblings $(\mathrm{OR}=2.19 ; 95 \% \mathrm{CI}: 1.40,3.44)$ and lower positive youth development at baseline $(\mathrm{OR}=-.67 ; 95 \% \mathrm{CI}$ : $0.50,0.92)$ were significantly associated with a higher risk of developing persistent depressive symptoms (Table 2 ). Age, gender, and migrant status at baseline were not significantly associated with the persistence of depression. For the familial level, students who lived in a nonintact family $(\mathrm{OR}=2.87 ; 95 \% \mathrm{CI}: 1.16,7.12)$ and with worse family functioning had a significantly greater likelihood of developing persistent depression $(\mathrm{OR}=0.74$; 95\% CI: 0.54, 1.10). Those whose father had a high educational level (bachelor's degree or above) experienced a protective effect, with a higher probability of remitting from depression $(\mathrm{OR}=-0.23$; 95\% CI: 0.07, 0.76) (Table 4).

\section{Discussion}

The present study investigated the prevalence of persistent depressive symptoms across 12 months among Chinese junior high school adolescents and simultaneously evaluated the influences of personal and familial factors on persistent depressive symptoms. In the present study, nearly half of the initially self-reported depressed students remained depressive during the course of a year. The prevalence of the persistent depression in this study is generally comparable with those reported by previous Western studies on adolescents [40-42]. The prevalence in the present study was relatively lower than that reported by Li et al. [12], possibly because the period of assessment in Li et al.'s study was shorter (9 months) compared to ours. Taken together, data collected from schools located in Shenzhen City generated results, which seem to coincide with those in the developed Western countries or in other economically equivalent areas (like Guangzhou city). More cross-cultural longitudinal studies are needed to substantiate the aforementioned intriguing findings associated with the level of economic development. The results of the present study may be primarily attributable to the fact that students have been in a more competitive academic environment [43]. It is widely recognized that persistent depression is associated with a range of mental illnesses like substance abuse, self-injury, and suicidal behavior [44] and has 
Table 3 Prevalence of persistent and remitted depressive symptoms across 12 months

\begin{tabular}{lccc}
\hline & $\begin{array}{l}\text { Prevalence of depressed } \\
\text { participants at baseline } \\
n\end{array}$ & $\begin{array}{l}\text { 12- month } \\
\text { persistence } \\
n / \%\end{array}$ & $\begin{array}{l}\text { 12- month } \\
\text { remission } \\
\mathrm{n} / \%\end{array}$ \\
\hline $\begin{array}{l}\text { All depression } \\
(\geq 16 \text { points) }\end{array}$ & 435 & $202 / 46.4$ & $233 / 53.6$ \\
\hline
\end{tabular}

posed unique challenges to society. As such, Chinese society urgently needs researchers, educators, parents, and policymakers to work together to adopt effective intervention programs to address the issue.

Concerning demographic factors, having siblings was found to significantly predict persistent depressive symptoms over 1 year. Specifically, adolescents from onechild families were more likely to remit from depressive symptoms over time than adolescents with siblings. In view of the resource dilution model, in single child families, greater parental resources such as attention, time, and energy provided by parents of single children may lead to better parental guidance and individual care. Such social support may help depressed children make better psychological and behavioral adjustments, which provides greater opportunity to remit from depression [45]. Moreover, the single child group promoted by the one-child policy is embedded in a unique cultural, social, and economic background that has historical causes. According to Huang et al. [46], single children in China who generally live in areas with a more developed economy have parents with a higher level of education, and therefore a better occupational background such as being staff members of a state-owned enterprise, or in government departments and institutions. These children, who are likely to be living in a Chinese registered residence - known as "Hukou" have the opportunity to experience a richer and more diverse extracurricular life and thus a more pleasant childhood, than those from rural areas. These factors may serve to protect their mental health, thereby reducing the likelihood of persistent depression.

The results of this study also showed that adolescents with a lower level of positive youth development were more likely to develop persistent depression. Such results are supported by developmental psychopathology framework and previous studies in western cultures [4749]. Thus, promoting positive youth development plays an essential role in protecting against depression. Under this condition, a number of interventional studies were conducted in North America and in Hong Kong, suggesting that positive youth development programs are associated with reduced problematic behaviors including depression, and additionally promotes positive development $[23,50,51]$. Moreover, several evidence-based interventions are found to be useful for prevention and treatment of persistent depression among adolescents, which include Treatment for Adolescents with Depression Study (TADS) and The Penn Resiliency Project (PRP) [52]. These interventions comprise of psychiatric and psychological components promoting mental health and addressing mental disorders among adolescents.

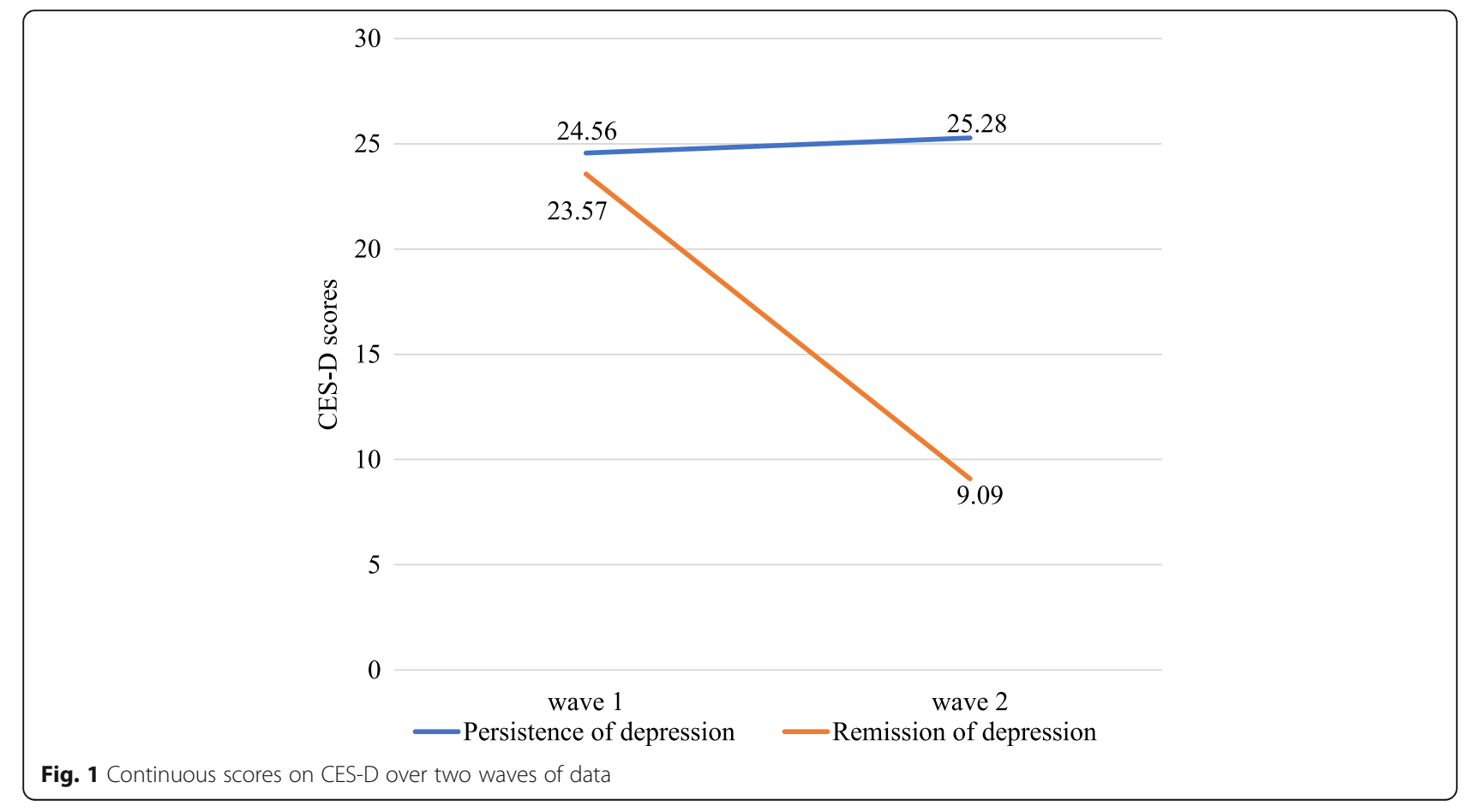


Table 4 Individual and familial characteristics of participants between remission of depression and persistence of depression across 12 months $(N=435)$

\begin{tabular}{|c|c|c|c|}
\hline \multirow[t]{3}{*}{ Predictors } & \multicolumn{2}{|l|}{ Across 12 months } & \multirow[t]{3}{*}{$t / x^{2}$} \\
\hline & $\begin{array}{l}\text { Remission of depression } \\
(\boldsymbol{N}=233)\end{array}$ & $\begin{array}{l}\text { Persistence of depression } \\
(\boldsymbol{N}=202)\end{array}$ & \\
\hline & $\mathrm{n} / \%(\mathrm{M} / \mathrm{SD})$ & $\mathrm{n} / \%(\mathrm{M} / \mathrm{SD})$ & \\
\hline \multicolumn{4}{|l|}{ Individual factors } \\
\hline Age & $12.47 / .64$ & $12.47 / .67$ & .08 \\
\hline Gender & & & .83 \\
\hline Male & $118 / 50.6$ & $92 / 45.5$ & \\
\hline Female & $114 / 48.9$ & $106 / 52.5$ & \\
\hline Missing & $1 / .4$ & $4 / 2.0$ & \\
\hline Siblings & & & $11.18 * *$ \\
\hline One Child & $98 / 42.1$ & $54 / 26.7$ & \\
\hline Non-one child & $135 / 57.9$ & $148 / 73.3$ & \\
\hline Missing & 0 & 0 & \\
\hline Migrant status & & & .72 \\
\hline Migrant students & $50 / 21.5$ & $50 / 24.8$ & \\
\hline Local students & 182/78.1 & $150 / 74.3$ & \\
\hline Missing & $1 / .4$ & $2 / .1$ & \\
\hline Positive Youth Development & $4.46 / .66$ & $4.25 / .73$ & $3.09^{* *}$ \\
\hline \multicolumn{4}{|l|}{ Familial factors } \\
\hline Family intactness & & & $7.09^{* *}$ \\
\hline Intactness & $222 / 95.3$ & 177/87.6 & \\
\hline Non-intactness & $10 / 4.3$ & $22 / 10.9$ & \\
\hline Missing & $1 / .4$ & $3 / 1.5$ & \\
\hline Father's Education Level & & & $9.26^{*}$ \\
\hline Less than or middle school & $76 / 32.6$ & $80 / 39.6$ & \\
\hline High school or college & $79 / 33.9$ & $63 / 31.2$ & \\
\hline University & $41 / 17.6$ & $29 / 14.4$ & \\
\hline More than university & $28 / 12.0$ & $9 / 4.5$ & \\
\hline Missing data & $9 / 3.9$ & $21 / 10.4$ & \\
\hline Mother's Education Level & & & 4.75 \\
\hline Less than or middle school & $97 / 41.6$ & $95 / 47.0$ & \\
\hline High school or college & $69 / 29.6$ & $55 / 27.2$ & \\
\hline University & $41 / 17.6$ & $22 / 10.9$ & \\
\hline More than university & $18 / 7.7$ & $11 / 5.4$ & \\
\hline Missing data & $8 / 3.4$ & 19/9.4 & \\
\hline Family Function & $3.85 / .77$ & $3.57 / .81$ & $3.75^{* * *}$ \\
\hline
\end{tabular}

However, such interventions are not widely adapted and implemented in the sociocultural context of China, which makes it unclear if these programs are also effective for addressing persistent depression or other diseasespecific conditions in this unique population.

Regarding the familial level, students who lived in non-intact families are more likely to report persistent depressive symptoms. Results indicate that non-intact family and greater paternal-only educational attainment may respectively be risk and protective factors for depression. Parental divorce or death can be very stressful life events for children [53, 54], and make it extremely difficult for depressed children to recover [55]. In addition, initially depressed adolescents whose fathers 
had higher educational levels (bachelor's degree and above) were more likely to remit from depression within 1 year. This is consistent with previous cross-sectional studies investigating the association between depression and parental educational level among Chinese children and adolescents $[22,56]$. One explanation is that fathers with higher educational levels are more aware of the significance of a father's influence and are more willing to put emotional and intellectual investment in parenting [22]. Conversely, fathers with low educational levels tend to adopt undesirable parenting strategies such as scolding and punishing [57]. Another possibility is that fathers with low educational levels are often busy with their livelihoods; many often have to travel far to work, or are away from home all year round. Thus, it may be difficult for them to have the time, energy, or resources to interact with their children [58]. These factors may increase the likelihood of mental health problems including persistent depressive symptoms in adolescents.

Further, poor family functioning strongly predicted a higher risk of persistent depressive symptoms, and adolescents from healthy functioning families were more likely to recover from depression. The results were similar to many cross-sectional and longitudinal studies, which have shown that healthy family functioning (e.g., strong family involvement, and open affective expression and communication) predicts fewer adolescent depressive problems $[59,60]$. However, dysfunctional family environments, such as those offering less support, more conflict, and less cohesion, are correlated with more depressive symptoms. Researchers have shown that poor family environments can lead to strong negative emotions in adolescents (e.g., anger, hostility, self-blame, and helplessness) [61]. In addition, in negative family environments adolescents may directly or indirectly receive negative feedback from family members, prompting them to adopt a negative view and form negative selfperceptions [62]. Such negative emotions and selfperceptions may increase the risk of persistent depression among adolescents. Findings in our present study indicated that even though adolescents suffered from depressive symptoms, those who had a positive family environment were more likely to recover.

Several limitations of this study must be acknowledged. First, the CES-D scale was used to measure depression with a sum score of more than 16 points being considered a depressed level. Given that this selfreported questionnaire is commonly used in general populations, future studies on this similar topic that additionally include diagnostic instruments administered by clinical psychologists or psychiatrists are encouraged. Second, students with CES $>=16$ in this study were not referred to mental health services. In future studies, researchers could consider offering parents and students the option to be approached if the student screen positive using the CES-D to facilitate early diagnosis and treatment. Third, adolescent depression symptoms were only examined at two time points over a one-year interval. The categorization of remission versus persistent depression may only reflect the students' status at one point in time and may be unstable. Future studies may explore the long-term developmental trajectories of depression in adolescence, by collecting more waves of data over a longer period, such as over the six-year period from Grade 7 to Grade 12. Fourth, the selfreporting approach taken by this study may be a limitation; adolescents may under-report their depressive symptoms because of social desirability. Future studies could include multiple reporting approaches, such as parent, teacher, or peer reports, to make the evidence more convincing. Fifth, the predictive factors of persistent depression in this study only include demographic information, a psychological factor (positive youth development) and family factors. According to the developmental psychopathology framework, family history of mood disorders (e.g., depression) and psychological vulnerability factors (e.g., childhood adversity and personality traits as neuroticism) were significantly correlated with persistence of depression [16]. Future research may contain multiple factors to provide a more comprehensive picture of persistent depression in Chinese adolescents. Finally, as the study was conducted in junior high schools in Shenzhen, a modern city of China, and the data in the rural area were unavailable, the results may not be generalizable to adolescents across China.

\section{Conclusion}

This study has several theoretical and practical implications. Concerning theoretical implications, this study adds to the knowledge on persistence/remission of depression through a longitudinal study of Chinese adolescents. Besides, the prevalence and predictors of persistence and remission of depression are important components of a developmental and psychopathological perspective of adolescent depression in China $[8,63]$. Regarding practical aspects, we found that, firstly, the prevalence of persistent depressive symptoms among adolescents in China is relatively high. This suggests that effective strategies to help youth prevent and reduce depression must be developed and implemented in order to promote mental health. Secondly, adolescents from families with siblings and with low levels of positive youth development need particular help to prevent and reduce the possibility of persistent depressive symptoms. The promotion of positive youth development in adolescents could be a promising direction in preventing/reducing persistent depression among adolescents in China. Thirdly, family-based approaches that pay attention to 
enhancing parenting capabilities and family relationships by raising understanding, communication, and warmth and reducing conflicts between parents and children, may provide a way for preventing or reducing persistent depression among the adolescents. Moreover, for the families where fathers are with low level education, the communities and schools may carry out workshops or activities about how to improve fathers' involvement with their children's development and academic achievement [64]. For example, these fathers may be encouraged to talk to his children about school life, communicate with teachers, participate in activities organized by the school, and have a reasonable expectation for his children [65].

\section{Abbreviations}

Cl: Confidence interval; PYD: Positive youth development; CES-

D: Epidemiologic Studies Depression Scale; CPYDS: The Chinese Positive Youth Development Scale; CFAl: The Chinese Family Assessment Instrument; TADS: Treatment for Adolescents with Depression Study; PRP: The Penn Resiliency Project

\section{Acknowledgements}

This research was conducted within more than 150 public junior high schools located in Shenzhen (Shenzhen Education Bureau, 2019). We would like to thank XLC and LYZ for designing the study and writing the protocol. We would like to thank XLC, HB, and FX for the recruitment and the data collection. We would like to thank AY form Massachusetts General Hospital (Boston) and MMH from Texas A\&M University (Texas) for English editing.

\section{Authors' contributions}

All authors contributed substantially and meaningfully to this study and the final manuscript. XLC and LYZ designed the study and wrote the protocol. $X \mathrm{LC}, \mathrm{HB}$, and $\mathrm{FX}$ led the recruitment and the data collection phase. $\mathrm{CL}$ conducted statistical analysis. XLC and LYZ wrote the first draft of the manuscript and all authors have approved the final manuscript.

\section{Funding}

The study was supported by the National Social Science Foundation (16CSH049). The funder, XC, participated in study designing, protocol writing, data collection, and draft writing.

\section{Availability of data and materials}

The dataset used in the analysis of this study is available upon reasonable request and with permission of Shenzhen University.

\section{Ethics approval and consent to participate}

This study was approved by the Research Ethics Committee of Shenzhen University and all subjects provided written informed consent in accordance with the Helsinki declaration. As all data was entered in a completely anonymized manner, consent to participate was not required.

\section{Consent for publication}

As completely anonymized observational data was used (see "Ethics approval and consent to participate"), consent for publication was not required.

\section{Competing interests}

The authors declare no conflicts of interest associated with this research study.

\section{Author details}

${ }^{1}$ Center for Lifestyle and Mental Health, School of Psychology, Shenzhen University, Shenzhen 518060, China. ${ }^{2}$ University of Electronic Science and Technology of China, Chengdu 610054, China. ${ }^{3}$ Exercise \& Mental Health Laboratory, School of Psychology, Shenzhen University, Shenzhen 518060 China. ${ }^{4}$ Texas A\&M University, College Station TX 77843, USA. ${ }^{5}$ Massachusetts General Hospital, Harvard Medical School, Boston, MA 02114, USA. ${ }^{6}$ Medical
University of Vienna, Kinderspitalgasse 15/1, 1090 Wien, Austria. ${ }^{7}$ Department of Social and Behavioural Sciences, City University of Hong Kong, Hong Kong, China. ${ }^{8}$ School of Nursing, Army Medical University, Chongqing 400038, China.

Received: 14 April 2020 Accepted: 3 August 2020

Published online: 12 August 2020

\section{References}

1. Glied S, Pine DS. Consequences and correlates of adolescent depression. Arch Pediatr Adolesc Med. 2002;156(10):1009-14.

2. Cook MN, Peterson J, Sheldon C. Adolescent depression: an update and guide to clinical decision making. Psychiatry (Edgmont). 2009:6(9):17-31.

3. Li G, Mei J, You J, Miao J, Song X, Sun W, Lan Y, Qiu X, Zhu Z Sociodemographic characteristics associated with adolescent depression in urban and rural areas of Hubei province: a cross-sectional analysis. BMC Psychiatry. 2019;19(1):386.

4. Hong L, Guo L, Wu H, Li P, Xu Y, Gao X, Deng J, Huang G, Huang J, Lu C. Bullying, depression, and suicidal ideation among adolescents in the Fujian Province of China: a cross-sectional study. Medicine (Baltimore). 2016;95(5): e2530.

5. Anyan F, Hjemdal O. Adolescent stress and symptoms of anxiety and depression: resilience explains and differentiates the relationships. J Affect Disord. 2016:203:213-20.

6. Fatori D, Bordin IA, Curto BM, de Paula CS. Influence of psychosocial risk factors on the trajectory of mental health problems from childhood to adolescence: a longitudinal study. BMC Psychiatry. 2013;13:31.

7. Shore L, Toumbourou JW, Lewis AJ, Kremer P. Longitudinal trajectories of child and adolescent depressive symptoms and their predictors - a systematic review and meta-analysis. Child Adolesc Mental Health. 2017;23:1-14.

8. Patten CA, Choi WS, Vickers KS, Pierce JP. Persistence of depressive symptoms in adolescents. Neuropsychopharmacology. 2001;25(5):S89-91.

9. Khandaker GM, Stochl J, Zammit S, Goodyer I, Lewis G, Jones PB. Childhood inflammatory markers and intelligence as predictors of subsequent persistent depressive symptoms: a longitudinal cohort study. Psychol Med. 2018;48(9):1514-22.

10. Steinhausen HC, Metzke CW. Prevalence of affective disorders in children and adolescents: findings from the Zurich epidemiological studies. Acta Psychiatr Scand Suppl. 2003;108(418):20-3.

11. Luyckx K, Rassart J, Goossens E, Apers S, Oris L, Moons P. Development and persistence of depressive symptoms in adolescents with CHD. Cardiol Young. 2016;26(6):1115-22

12. Li JB, Mo PKH, Lau JTF, Su XF, Zhang X, Wu AMS, Mai JC, Chen YX. Online social networking addiction and depression: the results from a large-scale prospective cohort study in Chinese adolescents. J Behav Addict. 2018;7(3): 686-96.

13. Garber J. Depression in youth: A developmental psychopathology perspective. In: Masten AS, editor. Minnesota symposia on child psychology. Multilevel dynamics in developmental psychopathology: Pathways to the future, vol. 34. Taylor \& Francis Group/Lawrence Erlbaum Associates; 2007

14. Cicchetti D, Rogosch FA, Toth SL. A developmental psychopathology perspective on depression in children and adolescents. In: Reynolds WM, Johnston HF, editors. Handbook of depression in children and adolescents (issues in clinical child psychology). New York: Plenum Press; 1994. p. 123-41.

15. George C, Herman KC, Ostrander R. The family environment and developmental psychopathology: the unique and interactive effects of depression, attention, and conduct problems. Child Psychiatry Hum Dev. 2006;37(2):163-77

16. Spijker J, de Graaf R, Bijl RV, Beekman AT, Ormel J, Nolen WA. Determinants of persistence of major depressive episodes in the general population. Results from the Netherlands mental health survey and incidence study (NEMESIS). J Affect Disord. 2004;81(3):231-40.

17. Wartberg L, Kriston L, Thomasius R. Depressive symptoms in adolescents: prevalence and associated psychosocial features in a representative sample. Dtsch Arztebl Int. 2018;115(33-34):549.

18. Mao Z-H, Zhao X-D. The effects of social connections on self-rated physical and mental health among internal migrant and local adolescents in Shanghai, China. BMC Public Health. 2012;12(1):97. 
19. Storksen I, Roysamb E, Holmen TL, Tambs K. Adolescent adjustment and well-being: effects of parental divorce and distress. Scand J Psychol. 2006; 47(1):75-84

20. Capron C, Therond C, Duyme M. Brief report: effect of menarcheal status and family structure on depressive symptoms and emotional/behavioural problems in young adolescent girls. J Adolesc. 2007;30(1):175-9.

21. Park AL, Fuhrer R, Quesnel-Vallee A. Parents' education and the risk of major depression in early adulthood. Soc Psychiatry Psychiatr Epidemiol. 2013; 48(11):1829-39.

22. Chen $Y$, Dai $Y$, Chen $H$, Yang $T$. The influence of father's upbringing participation on the mental health development of middle school students. Chin J Sch Health. 2015;263(11):134-7.

23. Shek DTL, Yu L. A review of validated youth prevention and positive youth development programs in Asia. Int J Adolesc Med Health. 2011;23(4):317-24.

24. Keitner Gl, Miller IW. Family functioning and major depression: an overview. Am J Psychiatry. 1990;147(9):1128-37.

25. Cano M, Schwartz SJ, Castillo LG, Unger JB, Huang S, Zamboanga BL, Romero AJ, Lorenzo-Blanco El, Córdova D, Des Rosiers SE, Lizzi KM, Baezconde-Garbanati L, Soto DW, Villamar JA, Pattarroyo M, Szapocznik J. Health risk behaviors and depressive symptoms among Hispanic adolescents: examining acculturation discrepancies and family functioning. J Fam Psychol. 2016;30(2):254-65.

26. Lewis AJ, Knight T, Germanov G, Benstead ML, Joseph Cl, Poole L. The impact on family functioning of social media use by depressed adolescents: a qualitative analysis of the family options study. Front Psychiatry. 2015;6:131.

27. Tompson MC, Connor EO, Kemp GN, Langer DA, Asarnow JR. Depression in childhood and early adolescence: parental expressed emotion and family functioning. Ann Depress Anxiety. 2015;2(7):1070.

28. Xu Z, Huang F, Kösters M, Rüsch N. Challenging mental health related stigma in China: systematic review and meta-analysis. II. Interventions among people with mental illness. Psychiatry Res. 2017;255:457-64.

29. Jiang L, Wang Y, Zhang Y, Li R, Wu H, Li C, Wu Y, Tao Q. The Reliability and Validity of the Center for Epidemiologic Studies Depression Scale (CES-D) for Chinese University Students. Front Psychiatry. 2019;10:315.

30. Yang $L$, Jia CX, Qin P. Reliability and validity of the Center for Epidemiologic Studies Depression Scale (CES-D) among suicide attempters and comparison residents in rural China. BMC Psychiatry. 2015;15:76.

31. Jewkes RK, Dunkle K, Nduna M, Jama PN, Puren A. Associations between childhood adversity and depression, substance abuse and HIV and HSV2 incident infections in rural south African youth. Child Abuse Negl. 2010; 34(11):833-41.

32. Radloff LS. The CES-D scale:a self-report depression scale for research in the general population. Appl Psychol Meas. 1977;1(3):385-401.

33. Liu C, Wei Y, Ling Y, Huebner ES, Zeng Y, Yang Q. Identifying trajectories of Chinese high school students' depressive symptoms: an application of latent growth mixture modeling. Appl Res Qual Life. 2019;21:1-5.

34. Park KH, Kim D-H, Kim SK, Yi YH, Jeong JH, Chae J, Hwang J, Roh $H$. The relationships between empathy, stress and social support among medical students. Int J Med Educ. 2015;6:103-8.

35. Shek DTL, Ma CMS. Dimensionality of the Chinese positive youth development scale: confirmatory factor analyses. Soc Indic Res. 2010;98(1): 41-59.

36. Shek DTL, Siu AMH, Lee TY. The Chinese positive youth development scale: a validation study. Res Soc Work Pract. 2007;17(3):380-91.

37. Shek DTL. Assessment of family functioning in Chinese adolescents: the Chinese version of the family assessment device. Res Soc Work Pract. 2002; 12(4):502-24.

38. Shek DTL, Yu L. Self-harm and suicidal behaviors in Hong Kong adolescents: prevalence and psychosocial correlates. Sci World J. 2012;2012:14

39. Lai Chong Ma J, Wong TKY, Lau LK, Pun SH. Perceived family functioning and family resources of Hong Kong families: implications for social work practice. J Fam Soc Work. 2009;12(3):244-63.

40. Brière FN, Janosz M, Fallu JS, Morizot J. Adolescent trajectories of depressive symptoms: Codevelopment of behavioral and academic problems. Adolesc Health. 2015;57(3):313-9.

41. Yaroslavsky I, Pettit JW, Lewinsohn PM, Seeley JR, Roberts RE. Heterogeneous trajectories of depressive symptoms: adolescent predictors and adult outcomes. J Affect Disord. 2013;148(2-3):391-9.

42. Fernandez Castelao C, Kroner-Herwig B. Different trajectories of depressive symptoms in children and adolescents: predictors and differences in girls and boys. J Youth Adolesc. 2013;42(8):1169-82.
43. Sun J, Dunne MP, Hou X-Y, Xu A-Q. Educational stress among Chinese adolescents: individual, family, school and peer influences. Educ Rev. 2013; 65(3):284-302

44. Rushton JL, Forcier M, Schectman RM. Epidemiology of depressive symptoms in the National Longitudinal Study of adolescent health. J Am Acad Child Adolesc Psychiatry. 2002;41(2):199-205.

45. Liu RX, Lin W, Chen Z-Y. School performance, peer association, psychological and behavioral adjustments: a comparison between Chinese adolescents with and without siblings. J Adolesc. 2010;33(3):411-7.

46. Huang Y, Li Y, Chen GC, Wu AY, Liu H, Huang X, Li J. Analysis of depression symptoms and its influencing factors in only and non only middle school students. Public Health China. 2011;27:984-6.

47. Olson JR, Goddard HW. Applying prevention and positive youth development theory to predict depressive symptoms among young people. Youth Soc. 2015;47(2):222-44.

48. Jeličić $H$, Bobek DL, Phelps E, Lerner RM, Lerner JV. Using positive youth development to predict contribution and risk behaviors in early adolescence: findings from the first two waves of the 4- $\mathrm{H}$ study of positive youth development. Int J Behav Dev. 2007;31(3):263-73.

49. Canning J, Denny S, Bullen P, Clark T, Rossen F. Influence of positive development opportunities on student well-being, depression and suicide risk: the New Zealand youth health and well-being survey 2012. Kōtuitui. 2017;12(2):119-33.

50. Catalano RF, Berglund ML, Ryan JAM, Lonczak HS, Hawkins JD. Positive youth development in the united states: research findings on evaluations of positive youth development programs. Ann Am Acad Polit Soc Sci. 2002; 5(1):98-124.

51. Catalano RF, Skinner ML, Alvarado G, Kapungu C, Reavley N, Patton GC, Jessee C, Plaut D, Moss C, Bennett K, Sawyer SM, Sebany M, Sexton M, Olenik C, Petroni S. Positive youth development programs in low- and middle-income countries: a conceptual framework and systematic review of efficacy. J Adolesc Health. 2019;65(1):15-31.

52. Cash RE, Valley-Gray S, Worton S, Newman A. Evidence-based interventions for persistent depressive disorder in children and adolescents. In: Theodore LA, editor. Handbook of Evidence-Based Interventions for Children and Adolescents. New York: Springer Publishing Company; 2017. p. 301-11.

53. Laukkanen M, Hakko H, Riipinen P, Riala K. Does family structure play a role in depression in adolescents admitted to psychiatric inpatient care? Child Psychiatry Hum Dev. 2016;47(6):918-24.

54. Yu Y, Yang X, Yang Y, Chen L, Qiu X, Qiao Z, Zhou J, Pan H, Ban B, Zhu X, He J, Ding Y, Bai B. The role of family environment in depressive symptoms among university students: a large sample survey in China. PLoS One. 2015; 10(12):e0143612

55. Hammen C. Stress and depression. Annu Rev Clin Psychol. 2005;1:293-319.

56. Xie S, Yu X, Wang Y, Yang S, Liu W, Ding H, Hu Y, Xu Y, Han J. Prevalence and correlation of early life stress and depression among adolescents in Wuhan city. Chin J Public Health. 2016:32(12):1680-3.

57. Van Holland De Graaf J, Hoogenboom M, De Roos S, Bucx F. Sociodemographic correlates of Fathers' and mothers' parenting behaviors. J Child Fam Stud. 2018;27(7):2315-27.

58. Lei $X$, Yang S, Liu L, Yang Y, Niu S. Effects of family upbringing style questionaire of grade 4-6 school children on depressive disorder. CJCHC. 2016:24(11):1152-5.

59. Sheeber L, Hops H, Alpert A, Davis B, Andrews J. Family support and conflict: prospective relations to adolescent depression. J Abnorm Child Psychol. 1997;25(4):333-44.

60. Ahookhosh P, Bahmani B, Asgari A, Hassanian-Moghaddam H. Family relationship and suicide ideation: the mediating roles of anxiety, hopelessness, and depression in adolescents. Int J High Risk Behav Addict. 2016;6:e31573.

61. Fosco GM, Grych JH. Emotional, cognitive, and family systems mediators of children's adjustment to interparental conflict. J Fam Psychol. 2008;22(6): 843-54.

62. Ingram RE. Origins of cognitive vulnerability to depression. Cogn Ther Res. 2003;27(1):77-88.

63. Cole DA, Peeke L, Dolezal S, Murray N, Canzoniero A. A longitudinal study of negative affect and self-perceived competence in young adolescents. J Pers Soc Psychol. 1999;77(4):851-62.

64. Lipscomb R. Strategies to improve fathers' involvement with their children's development and academic achievement. Race Gender Class. 2011:18(3/4): 253-67 Retrieved June 14, 2020, from www.jstor.org/stable/43496847. 
65. Benner A, Boyle A, Sadler S. Parental involvement and adolescents' educational success: the roles of prior achievement and socioeconomic status. J Youth Adolesc. 2016;45:1053-64.

\section{Publisher's Note}

Springer Nature remains neutral with regard to jurisdictional claims in published maps and institutional affiliations.

Ready to submit your research? Choose BMC and benefit from:

- fast, convenient online submission

- thorough peer review by experienced researchers in your field

- rapid publication on acceptance

- support for research data, including large and complex data types

- gold Open Access which fosters wider collaboration and increased citations

- maximum visibility for your research: over $100 \mathrm{M}$ website views per year

At $\mathrm{BMC}$, research is always in progress. 